\section{Micropropagation of Eucalyptus Species}

\author{
J.J. Le Roux and J. Van Staden \\ Foundation Research Development/University of Natal Research Unit for \\ Plant Growth and Development, Department of Botany, University of \\ Natal, Pietermaritzburg 3200, Republic of South Africa
}

Additional index words. Eucalyptus macarthurii, E. smithii, E. saligna, tissue culture, vegetative propagation, cold-tolerance

\begin{abstract}
Two cold-tolerant species (Eucalyptus macarthurii Deane et Maiden and $E$. smithii R.T. Baker), a cold-tolerant hybrid (E. macarthurii $\times$ E. grandis Hill ex Maiden), and $E$. saligna $\mathrm{Sm}$. were propagated in vitro from nodal explants collected from fieldgrown seedlings and from clonal hedges. Shoot growth was initiated on modified Murashige and Skoog (MS) medium containing BA at $0.1 \mathrm{mg} \cdot \mathrm{liter}^{-1}$. Modified MS medium

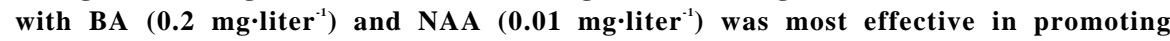
shoot proliferation. Root initiation was achieved on half-strength modified MS medium with $2 \mathrm{mg}$ IBA/liter. Rooted plants were hardened and established in the field. Chemical names used: N-(phenylmethyl)-1EZ-purin-6-amine (BA); 2-(1-naphthyl)acetic acid (NAA); 1H-indole-3-butyric acid (IBA).
\end{abstract}

The increasing demand for forest products has resulted in the need for greater yields from plantations. Vegetative propagation can provide clonal plantations of superior trees that produce greater yields than seedlingpropagated plantations (Zobel and Ikemori, 1983). Unfortunately, many of the Eucalyptus L' Her. species grown commercially, particularly the cold-tolerant ones, do not propagate easily by cuttings (McComb and Wroth, 1986). This study reports on the in vitro micropropagation of two cold-tolerant eucalyptus species (Eucalyptus macarthurii and $E$. smithii), a cold-tolerant hybrid ( $E$. macarthurii $\times E$. grandis) $(\mathrm{MG} 25)$, and $E$. saligna, which is somewhat cold-tolerant.

Shoots were collected from vigorously growing 1-year-old seedlings and l-year-old clonal hedges. The ortets of the clonal hedges were 5- to 10-year-old mature trees. Stock plants were sprayed with methyl[1-[(butylamino)carbonyl]-1H-benzimidazol-2-yl]carbamate (benomyl) (1 g.liter ${ }^{-1}$ ) twice weekly for 2 weeks before harvesting shoots. The

Received for publication 16 Feb. 1990. This project was supported by a grant from NTE Ltd and Mondi Forests. The cost of publishing this paper was defrayed in part by the payment of page charges. Under postal regulations, this paper therefore must be hereby marked advertisement solely to indicate this fact. fungicidal pretreatment was essential for effective decontamination of explants (data not shown)

Shoot lengths of two to three nodes were surface-disinfested by five rinses in sterile deionized water before and after a $15-\mathrm{min}$ treatment with $0.02^{\prime} \% \mathrm{HgCl}_{2}$ containing two or three drops of Tween 20 per $100 \mathrm{ml}$. Explants consisting of a single node with leaves trimmed near the base were placed upright in $25 \times 100-\mathrm{mm}$ glass vials containing 10 $\mathrm{ml}$ sterile initiation medium (IM). The IM consisted of Murashige and Skoog (MS) (1962) inorganic salts and vitamins and (all per liter) $1 \mathrm{~g}$ polyvinylpyrrolidone (PVP) (M.W. $\pm 70,000), 20 \mathrm{~g}$ sucrose, and $0.1 \mathrm{mg}$ BA. The medium was adjusted to $\mathrm{pH} 5.8$ before the addition of $2 \mathrm{~g}$ Gelrite/liter (Labretoria, Pretoria) and autoclave at 120C for $20 \mathrm{~min}$. Cultures were placed in the dark for 5 days at $25 \mathrm{C}$ and then transferred to a 16-h photoperiod under cool-white fluorescent light at $20 \mu \mathrm{mol} \cdot \mathrm{s}^{-1} \cdot \mathrm{m}^{-2}$ and a constant $25 \mathrm{C}$.

The number of surviving explants varied greatly between trials and depended largely on the condition of the stock plants. Stock plants producing young, healthy, vigorously growing shoots gave the best results. Shoots developed from axillary buds within 4 weeks in more than $90 \%$ of the surviving explants. These were transferred to shoot multiplica- tion medium (SMM) consisting of IM modified with (all per liter) $0.1 \mathrm{mg}$ calcium pantothenate, $0.1 \mathrm{mg}$ biotin, $0.1 \mathrm{~g}$ myo-inositol, and $0.01 \mathrm{mg}$ NAA, and various concentrations of either BA $(0.2,0.5$, or 1.0 mg.liter $\left.{ }^{-1}\right)$ or N-phenyl-N'-1,2,3,-thiadiazol-5-urea (thidiazuron; 0.1 or 0.2 $\left.\mathrm{mg} \cdot \mathrm{liter}^{-1}\right)$. Twenty-one explants were used for each treatment.

Shoot -proliferation for each species and treatment was determined as the change in shoot number over 28 days. Significance was determined by two-way analysis of variance and Tukey's highest significant difference range test. BA (0.2 mg.liter $\left.{ }^{-1}\right)$ with NAA $\left(0.01 \mathrm{mg} \cdot\right.$ liter $\left.^{-1}\right)$ proved to be the most effective treatment for promoting shoot multiplication for all species (Fig. 1). Explants on thidiazuron-amended media produced prolific callus that engulfed the developing shoots. Thidiazuron has been reported as a substitute for adenine-type cytokinins in micropropagation of woody species (van Niewkerk et al., 1986) and usually has higher biological activity than the most active adenine-type cytokinins (Mok et al., 1987). The concentrations of thidiazuron used in our trials were probably too high; however, lower concentrations were not tested, as BA at 0.2 $\mathrm{mg} \cdot$ liter $^{-1}$ gave satisfactory results.

No significant differences were found in the rates of shoot multiplication between species when compared over a total of 15 subcultures on media containing $0.2 \mathrm{mg} \mathrm{BA} /$ liter and $0.01 \mathrm{mg}$ NAA/liter, using one-way analysis of variance. and Tukey's range test $(P=0.05)$. The mean rates of shoot proliferation for E. macarthurii, E. smithii, E. saligna, and the hybrid MG25 were $3.0 \pm$ $0.5,2.5 \pm 0.5,3.4 \pm 0.4$, and $2.8 \pm 0.5$, respectively. A few shoots ( $1 \%$ to $5 \%$ ) became vitrified during each subculture, and callus formed at the nodes of some shoots, which resulted in apical senescence and leaf drop. These problems have also been reported for other Eucalyptus spp. (Franclet and Boulay, 1982) and could be minimized by precluding affected shoots from further subcultures. Although Gelrite has been reported to induce vitrification in some tissue cultures (Loreti and Pasqualetto, 1986), E. grandis shoot cultures were found to grow better on Gelrite than on agar (S. MacRae and J. Van Staden, unpublished data).

Elongated shoots $(<20 \mathrm{~mm})$ were transferred to root initiation medium that consisted of half-strength MS inorganic salts and 


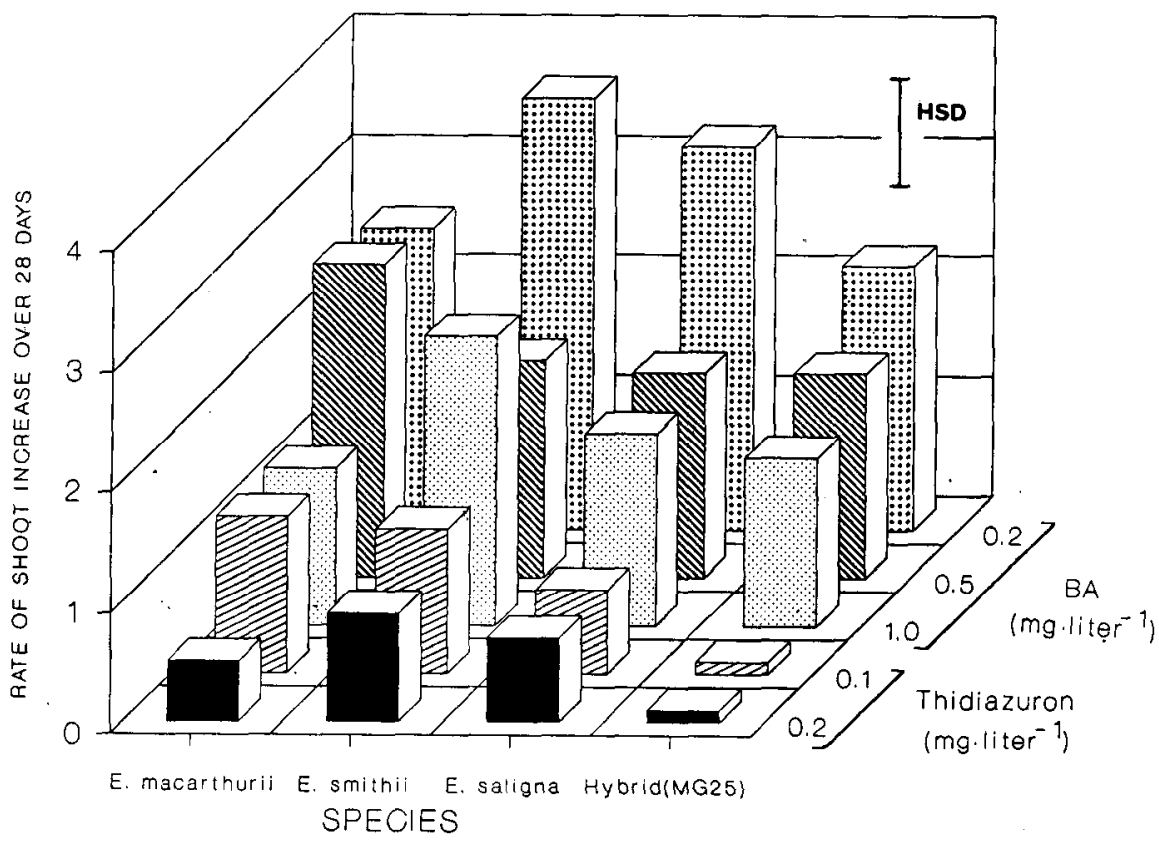

Fig. 1. Rates of axillary shoot proliferation from nodal explants of Eucalyptus spp. on modified Murashige and Skoog medium containing $0.01 \mathrm{mg}$ NAA/liter and various BA and thidiazuron concentrations. Values represent means of 21 samples. Separation by two-way analysis of variance, Tukey's range test, $P=0.05$.

vitamins, and (all per liter) $1 \mathrm{~g}$ PVP, $0.1 \mathrm{mg}$ calcium pantothenate, $0.1 \mathrm{mg}$ biotin, $0.1 \mathrm{~g}$ myo-inositol, $15 \mathrm{~g}$ sucrose, $2 \mathrm{mg}$ IBA, and $2 \mathrm{~g}$ Gelrite, $\mathrm{pH}$ 5.8. Cultures were placed in darkness for $72 \mathrm{~h}$ and then transferred to a 16-h photoperiod of lower light intensity (5 $\left.\mu \mathrm{mol} \cdot \mathrm{s}^{-1} \cdot \mathrm{m}^{-2}\right)$ at $25 \mathrm{C}$.

Roots became visible after 10 to 14 days in light. Roots often formed on small callus growths at the edges of leaves in contact with the medium; these plants could not be hardened. 'Therefore, the lower leaves on microcuttings should be removed before transfer to root initiation medium. Rooting ability of

shoots varied 'greatly for all species when comparing shoots from four sequential subcultures. Differences in rooting ability between species were significant $(P=0.05)$ in two out of four trials, and the range in rooting percentage was $0 \%-67 \%$ for $E$. $m a$ carthurii, 2\%-30\% for E. smithii, 21\%-100\% for E. saligna, and 9\%-86\% for the hybrid MG25.

Rooted shoots were transferred to a sterile potting mixture of 1 sand :1 bark :1 perlite (by volume) and hardened by gradually reducing the amount of intermittent mist (initially 5 sec every 15 rein) over 2 weeks.
More than $80 \%$ of the plantlets with suitable root systems survived. Established micropropagated plants had the same appearance as their ortets.

The technique for rooting of shoots requires further investigation, as E. macarthurii and E. smithii rooted poorly. These two species also root poorly from coppice cuttings (unpublished data). The micropropagation system described has potential either as a system for mass production of ramets for plantations or for the establishment of clonal hedges from which propagation by cuttings can be performed.

\section{Literature Cited}

Franclet, A. and M. Boulay. 1982. Micropropagation of frost resistant eucalyptus clones. Austral. For. Res. 13:83-89.

Loreti, F. and P.L. Pasqualetto. 1986. Vitrification of plants cultured in vitro. Proc. Intl. Plant Prop. Soc. 36:66-71.

McComb, J.A. and M. Wroth. 1986. Vegetative propagation of Eucalyptus resinifera and E. maculata using coppice cuttings and micropropagation. Austral. For. Res. 16:231-242.

Mok, M.C., D.W.S. Mok, J.E. Turner, and C.V. Mujer. 1987. Biological and biochemical effects of cytokinin-active phenylurea derivatives in tissue culture systems. HortScience 22:11941197.
Murashige, T. and F. Skoog. 1962. A revised medium for rapid growth and bioassays with tobacco tissue cultures. Physiol. Plant. 15:473497

van Niewkerk, J.P., R.H, Zimmerman, and L Fordham. 1986. Thidiazuron stimulation of apple shoot proliferation in vitro. HortScience 21:516-518

Zobel, B.J. and Y.K. Ikemori. 1983. Vegetative propagation in eucalypts, p. 136-144. $\ln$ : L. Zsuffa, R.M. Rauter, and C.W. Yeatman (eds.). Clonal forestry: Its impact on tree improvement and our future forests. Proc. 19th Meeting Canadian Tree Improvement Assn. Part 2. Toronto, Ontario. 